\title{
Metamaterial Based Square Bludgeon Shape Antenna for WLAN and WiMAX Applications
}

\author{
${ }^{{ }^{1}}$ K. V. Ajetrao, ${ }^{2}$ A.P. Dhande, ${ }^{3}$ Shailendra Shastri \\ ${ }^{* 1}$ Department of Electronics and Telecommunication. Dr. D. Y. Patil Institute of Technology, Pimpri, Pune \\ ${ }^{2}$ Department of Electronics and Telecommunication, Pune Institute of Technology, Pune \\ ${ }^{3}$ Department of Electronics and Telecommunication Thakur College of Engineering and Technology, Mumbai \\ Email: *kiran_ajetrao@rediffmail.com,apdhande@pict.edu, shastri_shailendra@rediffmail.com
}

Received: 20 ${ }^{\text {th }}$ March 2018, Accepted: 27 ${ }^{\text {th }}$ April 2018, Published: $30^{\text {th }}$ June $_{2018}$

\begin{abstract}
In this paper Split Ring Resonators are designed at two different frequencies and SRR are merged with monopole antenna designed at $3 \mathrm{GHz}$. This antenna shape looks like a weapon bludgeon hence it is named as square shape bludgeon antenna. The said antenna gives four different bands in the UWB range. Both the antennas can be used for WLAN and WiMAX applications as it covers both the frequencies. The complementary Split Ring Resonators are etched at ground surface to enhance the Bandwidth of antenna, and bandwidth enhancement is achieved at higher frequency. The metamaterial property of SRR is proved in first section of paper. The fabricated antennas tested using the vector network analyzer, the measured and simulated results are in good agreement with each other.
\end{abstract}

Keywords: Multiband Antenna, Split Ring Resonator Complementary Split Ring Resonator, VSWR , Radiation Pattern

\section{Introduction:}

As per the literature survey Metamaterials (MTMS) can be defined in various ways. Concept of metamaterial was initially introduced by the 'Veselago' in 1968 in his paper [1]. He defined metamaterials based on refractive index, Permittivity and permeability. As per his mathematical interpretation MTMs are defined as materials having negative permittivity and permeability. Recently many researchers are working in the same area and here some the authors defined metamaterials as, metamaterials can be synthesized by embedding artificially fabricated inclusions in a specified host medium or on a host surface [2] Electromagnetic metamaterials (MTMs) are broadly defined as artificial effectively homogeneous electromagnetic structures with unusual properties not readily available in nature [3] The concept of man-made structures known as metamaterials is discussed along with diverse applications, like stopping light and optical cloaking, The concept of split ring resonator and wire is also described [4] The concept of DPS(Double positive material, both $\varepsilon$ and $\mu$ are positive), DNG (Double negative material, both $\varepsilon$ and $\mu$ are negative),
ENG ( $\varepsilon$ is negative) and MNG ( $\mu$ is negative) is given in [5]. In this paper the concept of Split Ring resonator is used to load the monopole antenna. The split ring resonator gives the negative permittivity and permeability at $4.7 \mathrm{GHz}$ is proved by simulating it in Electromagnetic Simulator as shown in Figure 1. At presently many researchers are working on metamaterial antennas here are some of them summarised with the techniques adopted by them. In order generate metamaterial based multiband antennas. A compact tri-band planar monopole antenna is proposed that employs reactive loading and a "defected" ground-plane structure. The reactive loading of the monopole is inspired by transmissionline based metamaterials (TL-MTM), which enables the loaded antenna to operate in two modes find applications in WiFi and WiMAX. [6] [7]

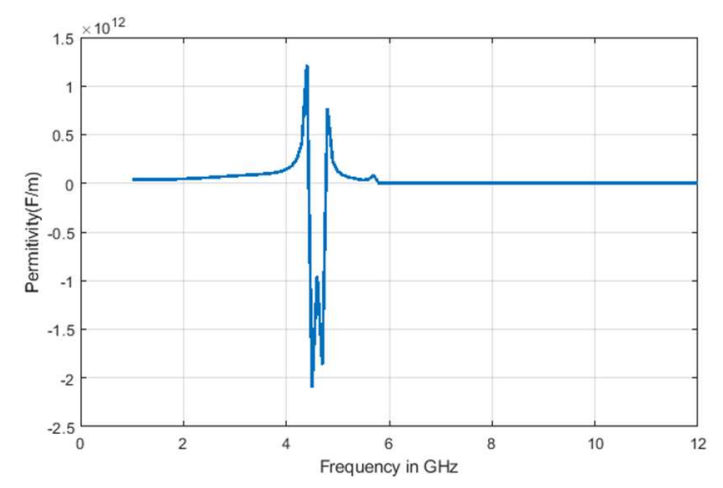

Figure 1: Negative Permittivity of Split Ring Resonator.

Small multiband planar antennas for wireless applications, enhanced by negative permeability metamaterial rings are created with the help of SRR. The presence of the rings results in a significant reduction of the operation frequency. In this Paper author used SRR with monopole to generate multiband operation [8][9] Compact, fully-printed negativerefractive-index transmission-line (NRI-TL) metamaterial-loaded dipole antenna is proposed, which exhibits multiband resonant characteristics that are not harmonically related [10][11] Composite rightand left-handed (CRLH) metamaterial transmission 
lines structure is proposed for compact multiband antenna design of a smart mobile phone.[12] [13][14][15]

This paper is divided in three sections as Introduction second sections covers design aspects of antenna and third section describes the result analysis of designed antenna.

\section{Antenna Design}

\subsection{Square Bludgeon Shape Antenna}

In the design of antenna two split ring resonators (SRR) designed at $4.7 \mathrm{GHz}$ and $6.2 \mathrm{GHz}$ are overlapped with the monopole antenna designed at $3 \mathrm{GHz}$. Height of monopole antenna will be $\lambda / 4$. In this design the height of monopole is optimized by changing the dimensions of the ground plane. The width of ground plane is increased to minimize the height of antenna. The antenna is named as bludgeon shape antenna as its appears like the weapon Gadaa used by characters in Mahabharata. The antenna is as shown in Figure 2. The optimized dimensions for the given antenna are as given in Table 1

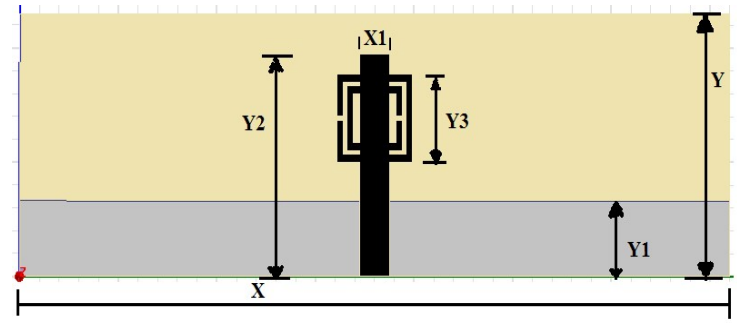

Figure 2: Square Bludgeon Shape Antenna 1

The dimensions of outer split ring resonator are $7.7 \mathrm{~mm} \times 7.7 \mathrm{~mm}$ with thickness of $0.7 \mathrm{~mm}$, so the overall length $30.8 \mathrm{~mm}$ and thickness $0.7 \mathrm{~mm}$ gives the equivalent inductance of outer ring. The slit gap of SRR is $0.3 \mathrm{~mm}$ and gap between the outer and inner SRR is $0.3 \mathrm{~mm}$, these gaps gives the overall capacitance for outer ring. Inner split ring dimensions are $6.5 \mathrm{~mm} \times 6.5 \mathrm{~mm}$ with thickness of $0.7 \mathrm{~mm}$ with overall legth of $26 \mathrm{~mm}$ gives equivalent inductance. Slit gap of $0.3 \mathrm{~mm}$ of inner SRR and gap between SRR and monopole gives the overall capacitance for inner SRR.

To calculate the resonace frequency of outer and inner SRR equation 1 and equation 2 are used respectively.

$f_{\text {SRR_out }}=\frac{1}{2 \pi} \sqrt{\frac{1}{L_{\text {SRR_oUT }} C_{\text {SRR_oUT }}}}$

$f_{S_{R R_{-} I N}}=\frac{1}{2 \pi} \sqrt{\frac{1}{L_{S R_{-} I N} C_{S R R_{-} I N}}}$
Where,

$f_{S R R_{-} \text {out }}$ : Resonance frequency of outer SRR

$L_{S R R_{-} \text {OUT }}$ : Equivalent Inductance of outer SRR

$C_{S R R_{-} \text {OUT }} \quad$ : Overall capacitance of outer SRR

$f_{S R R_{-} I N} \quad:$ Resonance frequency of outer SRR

$L_{S R R_{-} I N} \quad$ : Equivalent Inductance of outer

SRR

$C_{S R R_{-} I N}:$ Overall capacitance of outer SRR

Table 1. Square Bludgeon Shape Antenna.

\begin{tabular}{|l|l|l|}
\hline $\begin{array}{l}\text { Sr. } \\
\text { No. }\end{array}$ & Variable & $\begin{array}{l}\text { Dimension } \\
\text { in mm }\end{array}$ \\
\hline 1 & $\mathrm{X}$ & 72 \\
\hline 2 & $\mathrm{X} 1$ & 3 \\
\hline 3 & $\mathrm{Y}$ & 23 \\
\hline 4 & $\mathrm{Y} 1$ & 6.5 \\
\hline 5 & $\mathrm{Y} 2$ & 19.5 \\
\hline 6 & Y3 & 7.7 \\
\hline 7 & Thickness of SRR $(\mathrm{t})$ & 0.7 \\
\hline 8 & Gap between SRR $(\mathrm{gx})$ & 0.3 \\
\hline 9 & Slit gap of SRR & 0.3 \\
\hline
\end{tabular}

\subsection{Square Bludgeon Shape Antenna with CSRR at Ground Plane.}

The dimensions for the antenna will be same as of the square shape bludgeon antenna covered in section 2.1. Only change is seven Complementary Split Ring Resonators are added at the bottom plane of antenna. The radius of CSRR is $2.9 \mathrm{~mm}$ with thickness of etched width is $0.4 \mathrm{~mm}$. The slit gap of CSRR is $0.5 \mathrm{~mm}$. The both antennas are fabricated on FR4 substrate of thickness $1.6 \mathrm{~mm}$, dielectric constant of 4.4 , and loss tangent of 0.02 . The measured and simulated results are mismatched at higher frequencies. This mismatch is because of connector losses and errors during the fabrication. The square bludgeon shape antenna with CSRR at ground plane is as shown in Figure 3.

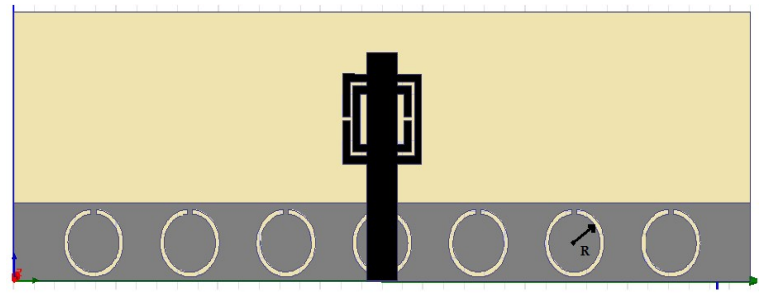

Figure 3: Square bludgeon Shape Antenna with CSRR at bottom.

\section{Results \& Discussion}

Square shape bludgeon shape antenna gives fours bands in the frequency range of $1 \mathrm{GHz}$ to $10 \mathrm{GHz}$. As UWB frequency range is $3.1 \mathrm{GHz}$ to $10.6 \mathrm{GHz}$, this antenna is also comes under the category of UWB antenna. From the Figure 4 it is clear that measured 
and simulated results are in good agreement with each other expect small mismatch at the higher frequency. The tuned frequencies are $3.1 \mathrm{GHz}, 4.7 \mathrm{GHz}, 6.2 \mathrm{GHz}$ and 7.8GHz. First two bands can be used for WLAN and WiMAX applications. Detailed analysis of results is given in Table 2 .

Figure 5 gives the VSWR values for the tuned frequencies. VSWR values should be in between 1 and 2. From Figure 5 it is clear that all values are in the said range.

Table 2. Square Bludgeon Shape Antenna Parameters.

\begin{tabular}{|l|l|l|l|l|}
\hline $\begin{array}{l}\text { Antenna } \\
\text { parameters. }\end{array}$ & \multicolumn{4}{|l|}{ SQUARE BLUDGEON SHAPE ANTENNA } \\
\hline $\begin{array}{l}\text { Frequency(G } \\
\text { Hz) }\end{array}$ & 3.1 & 4.7 & 6.2 & 7.8 \\
\hline $\begin{array}{l}\text { Bandwidth(G } \\
\text { Hz) }\end{array}$ & 1 & 1.4 & 0.3 & 0.7 \\
\hline S11(dB) & - & - & - & -11.98 \\
\hline VSWR & 20.68 & 23.03 & 16.37 & 1.67 \\
\hline $\begin{array}{l}\text { Impedance } \\
(\Omega)\end{array}$ & 42 & 44 & 67 & 50 \\
\hline
\end{tabular}

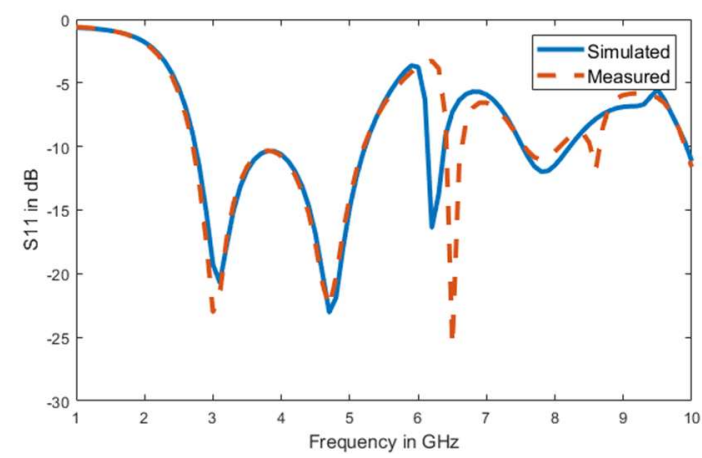

Figure 4: S11 vs Frequency Response for Square Bludgeon Shape Antenna

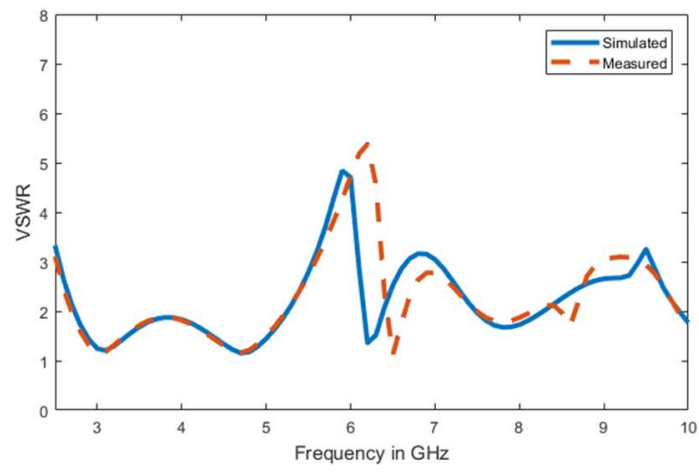

Figure 5: VSWR Plot for Square Bludgeon Shape Antenna

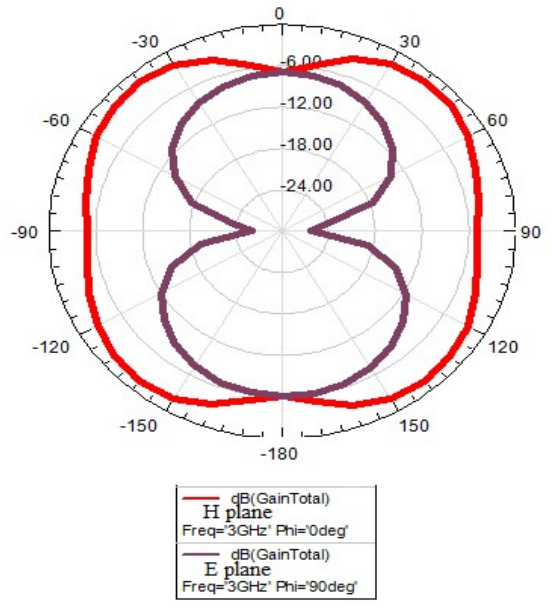

Figure 6: Radiation Pattern for Square Bludgeon Shape Antenna at $3 \mathrm{GHz}$

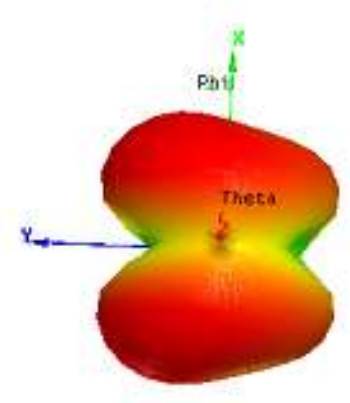

E-Plane

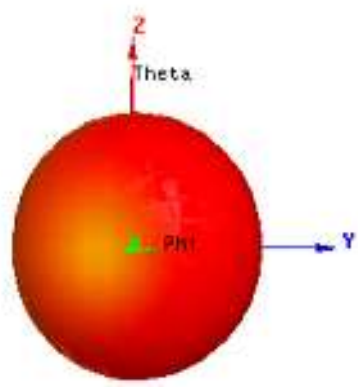

H-plane
Figure 7: 3D Radiation Pattern for Square bludgeon Shape Antenna at $3 \mathrm{GHz}$
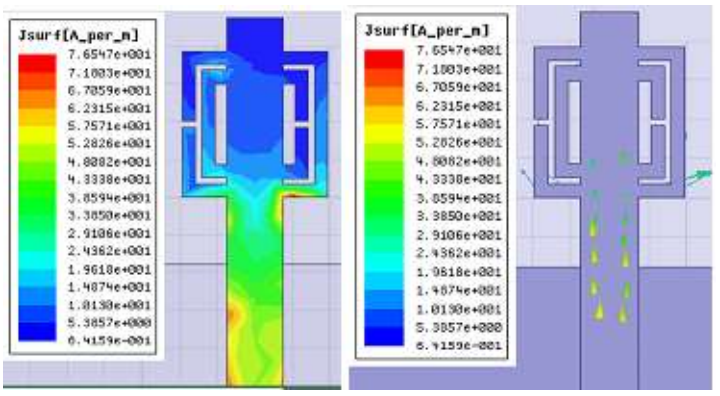

Figure 8: Current Distribution for Square Bludgeon Shape Antenna at $\mathbf{3 G H z}$

Figure 6 and Figure 7 shows the radiation pattern at $3 \mathrm{GHz}$. From both the patterns it is clear that E-plane pattern is like the dipole antenna and H-plane pattern in omnidirectional in nature. Figure 8 shows the current distribution and vectors are showing that antenna is radiating. The gain of antenna is low as it is 
micro strip antenna hence such kind of antennas can be used as receiver antennas.

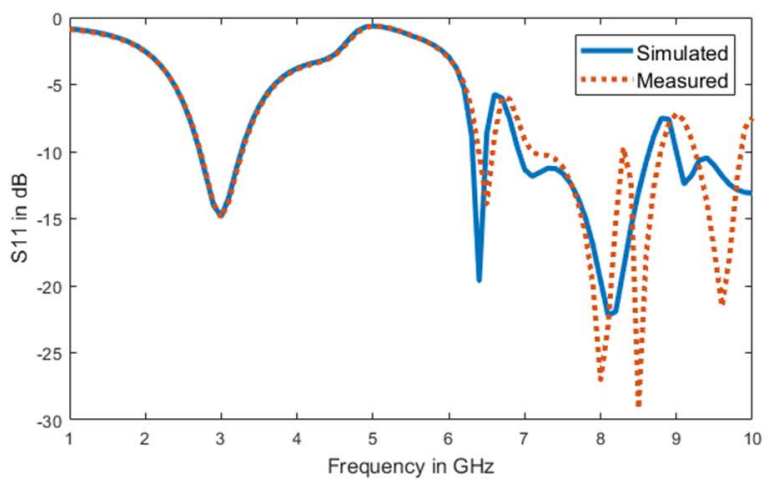

Figure 9: S11 vs Frequency for Square Bludgeon Shape Antenna with CSRR at Ground Plane.

When CSRR is etched in the ground plane of square bludgeon shape antenna, it also gives the four bands but Ultra Wide Band is achieved at higher frequency band as shown in Figure 9. The detailed analysis of graph for VSWR, Impedance is as given in Table 3. Figure 10 gives the VSWR plot for the same antenna. VSWR is nearly 1 for all tuned frequency bands. Figure 11 and Figure 12 shows the radiation pattern at $3 \mathrm{GHz}$ from the radiation pattern it is clear that in EPlane pattern is like dipole and H-Plane pattern is like omnidirectional antenna. Figure 13 shows the fabricated antennas.

Table 3. Square Bludgeon Shape Antenna with CSRR at Bottom Plane (Parameters).

\begin{tabular}{|l|l|l|l|l|}
\hline $\begin{array}{l}\text { Antenna } \\
\text { parameters. }\end{array}$ & \multicolumn{4}{l|}{$\begin{array}{l}\text { SQUARE BLUDGEON SHAPE ANTENNA } \\
\text { WITH CSRR }\end{array}$} \\
\hline $\begin{array}{l}\text { Frequency(G } \\
\mathrm{Hz})\end{array}$ & 3.0 & 6.4 & 8.2 & 9.1 \\
\hline $\mathrm{S} 11(\mathrm{~dB})$ & - & - & - & -12.40 \\
\hline VSWR & 14.82 & 19.64 & 22.22 & \\
\hline Bandwidth & 0.6 & 0.2 & 1.8 & 0.4 \\
\hline $\begin{array}{l}\text { Impedance } \\
(\Omega)\end{array}$ & 31 & 33 & 33 & 38 \\
\hline
\end{tabular}

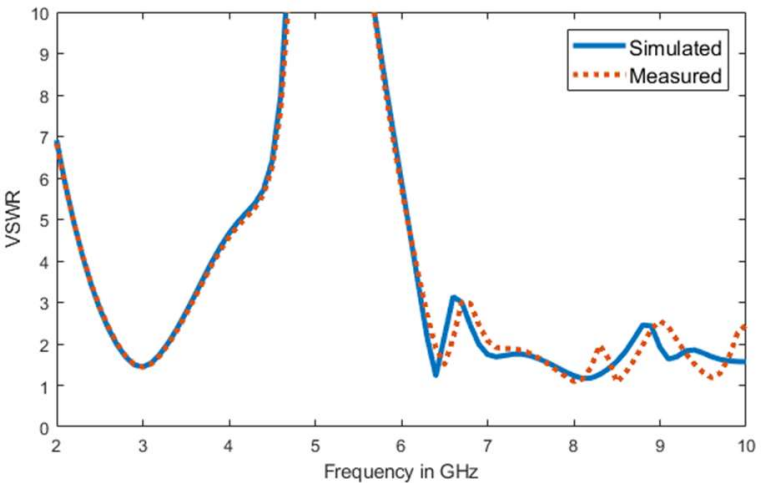

Figure 10: VSWR Plot for Square Bludgeon Shape Antenna with CSRR at Ground Plane.

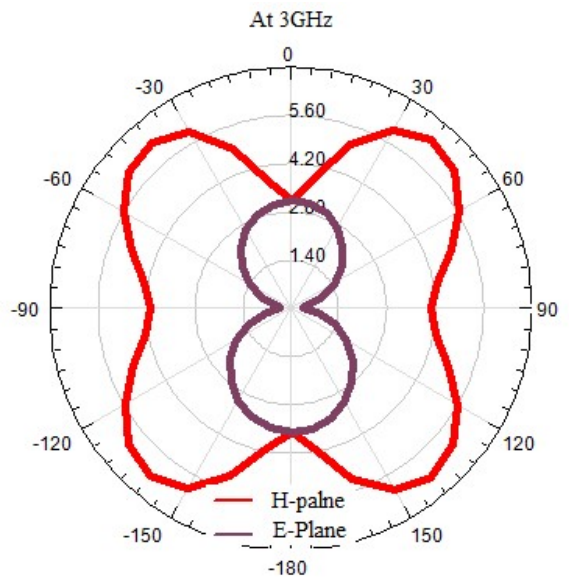

Figure 11: Radiation Pattern for Square Bludgeon Shape Antenna with CSRR at Ground Plane at $3 \mathrm{GHz}$

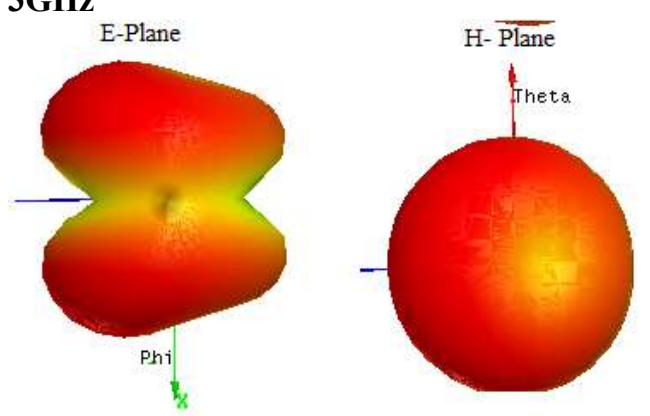

Figure 12: 3D Radiation Pattern for Square Bludgeon Shape Antenna with CSRR at Ground Plane at 3GHz. 

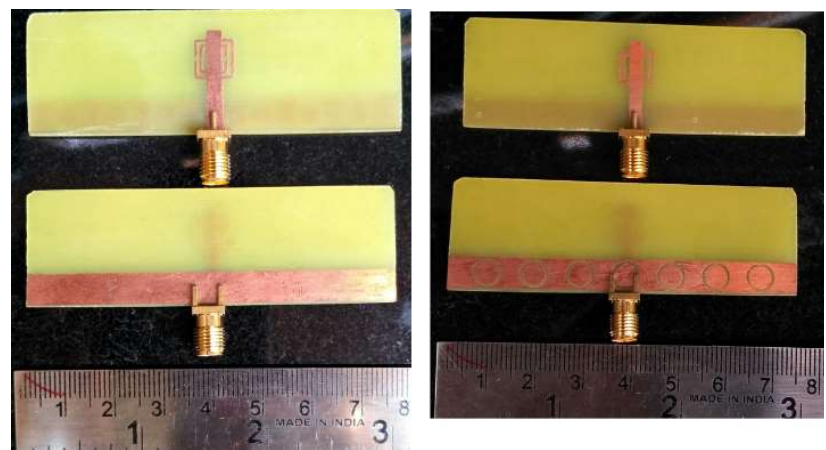

Figure 13: Fabricated Antennas.

\section{Acknowledgment}

The authors would like to thank faculties and staff members of Microwave laboratory, Electronics and Telecommunication Department, Pune Institute of computer Technology, Pune, for providing facility for antenna measurement on ROHDE \& SCHWARZ ZVL-Vector Network Analyzer.

\section{Conclusion}

In this paper Split Ring Resonators are used to design the radiating patch of antenna. The ground plane of antenna is defected with CSRR to enhance the bandwidth of antenna. Metamaterial property of SRR is proved by showing negative permittivity at $4.7 \mathrm{GHz}$. Both the antennas resonate at four different frequencies. First two band finds applications in WLAN and WiMAX applications. Finally antennas are fabricated on FR4 substrate and measured using ROHDE \& SCHWARZ ZVL-Vector Network Analyzer. Measured and simulated results of antennas are in good agreement with each other.

\section{References}

1. V. G. Veselago, "The electrodynamics of substances with simultaneously negative Values of $\varepsilon$ and $\mu$ ", Soviet Physics Uspekhi, Volume 10, Number 4, January-February, 1968

2. Nader Engheta, Richard W. Ziolkowski, "Metamaterials Physics and Engineering Explorations" A John Wiley \& Sons , Inc., Publications, 2006

3. Christophe Caloz, Tatsuo Itoh "Electromagnetic Metamaterials: Transmission line Theory and Microwave Applications, The Engineering Approach", A John Wiley \& Sons , Inc., Publications, 2006

4. M. S. Wartak, K.L. Tsakmakidis and O. Hess, "Introduction to metamaterials", Physics in Canada, Vol 67, No. 1 Jan-Mar-2011

5. Slyusar V.I. "Metamaterials On Antenna Solutions", International Conference on Antenna Theory and Techniques, Lviv, Ukraine, Page no.19-24, , 6-9 October, 2009
6. Jiang Zhu, , Marco A. Antoniades, , and George V. Eleftheriades, "A Compact Tri-Band Monopole Antenna With Single-Cell Metamaterial Loading", IEEE Transactions On Antennas And Propagation, Vol. 58, No. 4, April 2010

7. He Huang, Ying Liu, , Shaoshuai Zhang, and Shuxi Gong, "Multiband Metamaterial-Loaded Monopole Antenna for WLAN/WiMAX Applications", IEEE Antennas And Wireless Propagation Letters, Vol. 14, 2015

8. He Huang, Ying Liu, , Shaoshuai Zhang, and Shuxi Gong, "Multiband Metamaterial-Loaded Monopole Antenna for WLAN/WiMAX Applications", IEEE Antennas And Wireless Propagation Letters, Vol. 14, 2015

9. In Kwang Kim, , Huan Wang, , Steven J. Weiss, , and Vasundara V. Varadan, ,"Embedded Wideband Metaresonator Antenna on a HighImpedance Ground Plane for Vehicular Applications", IEEE Transactions On Vehicular Technology, Vol. 61, No. 4, May 2012

10. Marco A. Antoniades, , and George V. Eleftheriades, "Multiband Compact Printed Dipole Antennas Using NRI-TL Metamaterial Loading", IEEE Transactions On Antennas And Propagation, Vol. 60, No. 12, December 2012

11. S. Jamilan, M. A. Antoniades, J. Nourinia, and M. N. Azarmanesh, "A Compact Multiband Printed Dipole Antenna Loaded

12. With Two Unequal Parallel NRI-TL Metamaterial Unit Cells", IEEE Transactions On Antennas And Propagation, Vol. 63, No. 9, September 2015

13. Long Li, Zhen Jia, Feifei Huo, and Weiqiang Han "A Novel Compact Multiband Antenna Employing Dual-Band CRLH-TL for Smart Mobile Phone Application", IEEE Antennas And Wir eless Propagation Letters, Vol. 12, 2013

14. Ahmed Soliman, Dalia Elsheakh, Esmat Abdallah, and Hadia El-Hennawy, "Multiband Printed Metamaterial Inverted-F Antenna (IFA) for USB Applications", IEEE Antennas And Wireless Propagation Letters, Vol. 14, 2015

15. Mohammad Bemani, Saeid Nikmehr, , and Mahdi Fozi, "A Dual-Band Feed Network for Series-Fed Antenna Arrays Using Extended Composite Right/Left- Handed Transmission Lines", IEEE Transactions On Antennas And Propagation, Vol. 65, No. 1, January 2017

16. Xiang Gao, Timothy James Jackson, and Peter Gardner, "Multiband Open-Ended Resonant Antenna Based on One ECRLH Unit Cell Structure" IEEE Antennas And Wireless Propagation Letters, Vol. 16, 2017 
Helix Vol. 8(4): 3442- 3447

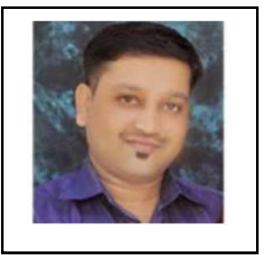

\section{Mr. Kiran Ajetrao}

Kiran V. Ajetrao received the B.E. degree in Electronics and Telecommunication from Shivaji University., in 2003. M.E. degree in Electronics and Telecommunication from the Shivaji University , Kolhapur, India, in 2010. He worked as Assistant Professor in Electronics and Telecommunication in Thakur College of Engineering and Technology from 1st January, 2010 to 30th June, 2012. He also worked as Lecturer in Electronics and Telecommunication Engineering from 23rd January, 2006 to 31 st December 2009. Presently he is pursuing $\mathrm{PhD}$ from Pune University. He is life time member of ISTE and area of interest is antennas and microwave engineering

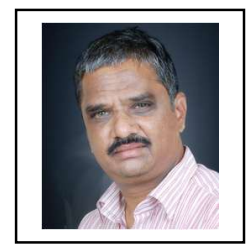

Dr. A. P. Dhande Presently he is working as Professor with Department of Electronics and Telecommunication Engineering, Pune institute of Technology, Pune. He has completed his ME and $\mathrm{PhD}$ in 1999 and 2007 respectively. $\mathrm{He}$ is member of IETE, ISTE, and member of Astronomical society of India (ASI). His areas of interest are Astronomy, Microwave engineering, antennas and published multiple papers in these areas in various reviewed journals time to time.

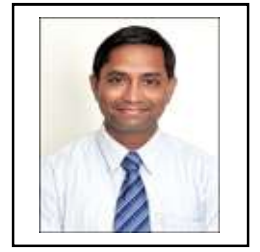

\section{Mr. Shailendra Shastri}

Shailendra P. Shastri received the B.TECH. degree from the Dr. B.A.T. University, Raigad, Maharashtra, India., in 2001, the M.E. degree from the Shivaji University, Kolhapur, India, in 2010, and currently doing Ph.D. from Pacific University, Rajasthan, India. From 2001 to 2005, he was working as lecturer in the department of Electronics and telecommunication at Rizvi College of Engineering, Bandra, Mumbai400050, India. He is working as Assistant Professor since 2005 